Child protection

\section{Child protection in sport}

\section{Turner, P McCrory}

\section{All sports authorities need to be aware of the problem of child abuse and have guidelines to ensure that such problems are minimised}

n

recent times, we have seen widespread publicity given to domestic

child abuse in the lay press, and there is every reason to suspect that sport is not immune from this problem. In Australia for example, a well known international cricket umpire was recently jailed for child sex allegations made when he was a schoolteacher. In 2001, a UK based tennis coach was jailed for seven years (with a further five years under licence) for child abuse, and, in America, a number of junior baseball and football coaches have been jailed for similar offences. ${ }^{1}$

As sports medicine professionals and parents, we have a duty to ensure that children participating in sport do so in an environment that is both enjoyable and safe. The very nature of sporting events means that athletic children are potentially at risk from such activitiessports clothing is often "minimal", showers and changing rooms are places where adults can mix with children, and children may be entrusted to the care of adults about whom the parents know very little. Organisations need to have procedures in place to prevent paedophiles or other undesirable people becoming involved with officiating, coaching, or supervising children and also have guidelines that enable young people to seek help and/or support on a confidential basis for any issue relating to child protection.

Child protection is not just about protecting children, it is also about ensuring coaches and officials are not the subject of unwarranted or malicious accusations.

In Great Britain, the Lawn Tennis Association (LTA) has been running a child protection programme since January 1997, and all the information provided in this paper relates to the experience gained in the first five years of this initiative. The programme was first introduced when the basic tennis coaching qualification (Development Coaching Award) gained accreditation as part of a National Vocational Qualification (NVQ). The NVQ required all coaches to become part of a child protection programme, a move that led to the swift identification of an abuser.

There are now 2398 tennis coaches who hold a recent (since 1997) LTA coach licence, a qualification that the LTA is keen for all coaches to acquire. Coaches holding the licence were initially checked for child protection issues through referencing, but, since April 2002, the LTA has required all licensed coaches to hold an Enhanced Disclosure Certificate from the United Kingdom Criminal Records Bureau. This provides details of all previous convictions including cautions and convictions for child abuse offences.

PLAYERS, CLUBS, AND COACHES

There are currently around 2.8 million tennis players in Great Britain, 50\% of whom are under the age of 25 , and $20 \%$ of whom have received some formal tennis coaching in the last 12 months. There are 2467 tennis clubs (with 373918 members) and 3147 LTA licensed coaches. In surveys of player attitudes, the stated reasons for playing tennis are enjoyment of the sport, keeping fit, and social opportunities. An average of 25 days of tennis per person is played each year. Novices account for $54 \%$, and only $3 \%$ of players have an LTA rating - that is, have played in an LTA sanctioned tennis competition. About 23458 junior players currently have an LTA rating.

\section{CHILD PROTECTION ISSUES}

In other sports, notably swimming, the type of offence documented has involved a male coach with female pupils. In tennis, similar cases have been recorded, but the great majority have involved multiple offences by a male coach on a number of male pupils (usually aged 8-15).

In Great Britain, it is estimated that the number of convicted paedophiles is about 1 per 300-400 adult men in the population. This calculation is based on the number of convicted paedophiles (about 50000 ) out of the total adult male population. The true incidence of paedophilia is not known, however; the figure above is likely to be an underestimate.

In the first five years of the LTA experience, 72 cases have raised "cause for concern", and 10 custodial sentences have been recorded. The longest custodial sentence has been seven years, with an additional five years under licence and a lifetime ban on working with children. Ninety percent of the LTA cases involve coaches and the remainder involve club "officials".

During the same period, there has been only one recorded case of a false accusation. The parents of a female player discovered a romantic diary and made a complaint against the coach concerned. Investigations by the police revealed that the events could not have taken place, and the girl subsequently admitted that the romance recorded in the diary had been fabricated.

\section{LTA POLICY DEVELOPMENT}

The LTA is at the forefront in the establishment and implementation of child protection policies within sport and has developed rigorous procedures to deal with this issue.

The child protection policy provides a comprehensive framework of best practice within the sport and directly assists individual tennis clubs to play a part in reducing this potential problem in their club. This policy includes guidelines and codes of conduct for those working with children in tennis, club policy statements, child protection awareness training, guidelines on selection and recruitment of club coaches and officials, and suggested self declaration forms for people applying for such positions.

The Coach Education Director at the LTA manages all complaints of child abuse in tennis. Each complaint is investigated and progressed in a manner that involves working with the player, his/her family, the police, and sometimes the Department of Social Services. The exact process varies from case to case, depending on the nature and extent of the allegations. Once the police are involved, much of the Coach Education Director's time is spent with club officials and other coaches, trying to help to resolve the many issues that arise in the club. If a complaint against an LTA licensed coach is substantiated, either by a conviction or through irrefutable evidence, the coach would have their licence revoked and, in the case of employed staff, would lose their job.

\section{GOVERNMENT LEGISLATIVE FRAMEWORK}

In October 1999, Sport England in partnership with the National Society for the Prevention of Cruelty to Children 
(NSPCC) acknowledged the problems besetting sport and launched the Child Protection in Sport Unit (CPSU). This is based at Leicester and has a remit to:

- act as a first point of call for sports organisations

- coordinates the production of literature and training

- commission research into a range of issues relating to child protection

- develop cross sport standards relating to standards and training.

It can be accessed on www.sportprotects. org.uk. It acts in addition to the other UK governmental authorities with responsibility for regulatory oversight of child protection issues. Further details on these can be obtained through the relevant website at www.doh.gov.uk/ safeguardingchildren/index.htm.

\section{DISCUSSION}

Sport can, through practical necessity, provide an environment suited to paedophiles, and the widely publicised cases have highlighted the fact that these people have often been abusing children for many years before they are finally prosecuted. Coaches in particular have enormous power and influence over young players, and there are ample opportunities for coaches to manipulate this situation should they wish to do so.

Sporting organisations are often reluctant to acknowledge that child abuse could be taking place within their jurisdiction, and, indeed, most have no mechanism to deal with complaints of abuse against staff or coaches. The sad fact is that the person concerned is often asked to find another job elsewhere, and no record of the complaint is actually recorded or made available to the next employer. When someone is charged with an offence, it is depressingly common to find a long trail of similar allegations (which were never reported or acted on) when the previous employers around the country/globe are contacted.

Unfortunately, this type of behaviour fails to be "cured" by a custodial sentence, and all too often these individuals seek further contact with children when they leave prison. Being unable to work with junior tennis players does not prevent someone seeking a job working with juniors in another sport.

All sports authorities need to be aware of such problems and have in place guidelines to ensure that such problems are minimised. Such policies need to be comprehensive and cover aspects such as codes of conduct for those working with children, club policy statements, child protection awareness training, guidelines on selection and recruitment of club coaches and officials, and suggested self declaration forms for people applying for such positions. Medical staff involved in junior sports programmes should be vigilant at all times to the possibility of child abuse and make sure that the organisations for whom they work have appropriate, documented mechanisms to investigate and process cases of child abuse brought to their attention. The LTA's child protection programme is at the forefront of best practice in this regard.

Br J Sports Med 2004;38:106-107. doi: 10.1136/bjsm.2004.012096

\section{..............}

Authors' affiliations

M Turner, The Lawn Tennis Association, The

Queens Club, London W14 9EG, UK

P McCrory, British Journal of Sports Medicine, Melbourne, Australia

Correspondence to: Dr Turner, The Lawn Tennis Association, The Queens Club, Palliser Road, London W14 9EG, UK; michael.turner@LTA. org.uk

\section{REFERENCE}

1 Nack W, Yaeger D. Every parent's nightmare. Sports Illustrated 1998;Sep 13:1-15. 